\title{
ORGANIZACIÓN, TERRITORIO Y SISTEMA PARTIDARIO: DIFUSIÓN TERRITORIAL DE LA ORGANIZACIÓN DE LOS PARTIDOS Y SUS POTENCIALES IMPACTOS SOBRE LA ESTRUCTURA DEL SISTEMA PARTIDARIO EN BRASIL Organization, territory and party system: territorial diffusion of party organization and its potential impacts on the structure of the party system in Brazil
}

\author{
María do Socorro SOUSA BRAGA \\ Universidade Federal de São Carlos, Brasil \\ $\triangle$ msbraga2009@gmail.com
}

Rodrigo RODRIGUES-SILVEIRA

Universidad de Salamanca, España

$\triangle$ rodrodr@gmail.com

Tiago BORGES

Universidade de São Paulo

\tiagodaher@gmail.com

BIBLID [1130-2887 (2012) 62, 15-45]

Fecha de recepción: 5 de marzo del 2012

Fecha de aceptación: 5 de septiembre del 2012

RESUMEN: ¿Cuál es el patrón territorial de la organización de los partidos brasileños? ¿Qué relación presenta con la estructura del sistema partidario? Para responder a dichas cuestiones, este artículo posee tres objetivos. Primero, investigar el patrón sistemático de organización y afiliación partidaria. Segundo, llevar a cabo un análisis exploratorio de la distribución territorial de la organización de los partidos brasileños. Tercero, producir hipótesis sobre relaciones causales entre organización partidaria, estructura del sistema y desempeño electoral. Teóricamente, este trabajo se basará en los estudios de Panebianco (2005 [1988]), así como empleará de modo extensivo análisis más recientes como los de Katz y Mair (1995) y Gunther y Diamond (2001). La metodología empleada será, predominantemente, el análisis exploratorio espacial de datos. Los resultados revelan que ha habido un movimiento constante de expansión de las bases de afiliación de los partidos y se manifiesta una diferencia estructural en la organización de los grandes partidos nacionales y los pequeños partidos, de carácter regional y con pequeña capacidad de atracción del electorado a sus filas.

Palabras clave: partidos políticos brasileños, territorialidad de los partidos, análisis espacial, afiliación partidaria. 
ABSTRACT: What is the territorial pattern of Brazilian political parties? What kind of relation this spatiality present with the party system? In order to answer these questions, this articles focus on three main objectives. Firstly, it will investigate the systematic pattern of political organization and affiliation in Brazilian municipalities. Secondly, it will perform an exploratory analysis of the spatial distribution of the political parties' organization in Brazil. Third, it will produce some tentative hypotheses concerning the causal relations between party organization, party system structure, and electoral performance. Teoretically, this work will be based on the work of Panebianco (2005 [1988]), as well as it will employ extensively some more recent analyses such as those from Katz and Mair (1995) and Gunther and Diamond (2003). The methodology used will, most of all, perform an Exploratory Spatial Data Analysis (esda). The results reveal that there were a constant movement towards expansion of party affiliation in Brazilian territory and it is manifested through a structural difference between large (with national territorial coverage) and small parties (mostly regional) in terms of party organization.

Key words: Brazilian political parties, party territoriality, spatial analysis, party affiliation.

\section{INTRODUCCIÓN ${ }^{1}$}

¿Cuál es el patrón territorial de la organización de los partidos brasileños? ¿Qué relación presenta con la estructura del sistema partidario o el desempeño electoral de los partidos? Resulta común encontrar evaluaciones negativas y temerosas sobre el funcionamiento de los sistemas políticos suramericanos, caracterizados normalmente como frágiles y susceptibles a la influencia de liderazgos personalistas. Aun con la consolidación de muchas democracias luego de largos períodos autoritarios, la desconfianza sobre la vitalidad y calidad de las democracias de la región persiste.

Dentro de ese ambiente, los partidos políticos han sido normalmente señalados como parte de ese sistema de baja calidad que, en algunos casos, conserva rasgos de inestabilidad: institucionalmente frágiles y desorganizados, localistas, poco pragmáticos, clientelares, los partidos presentarían y reforzarían características patológicas en las recientes democracias latinoamericanas.

Por otra parte, a pesar de la considerable expansión observada en la literatura sobre partidos políticos, la producción todavía resulta muy escasa en lo que se refiere a la estructura territorial de la organización de los partidos desde una perspectiva sistémica. Aunque existan referencias o deducciones (insights) en los más importantes trabajos en el área, pocos han sido los estudios que lidian empíricamente con el tema. Posiblemente, se trata de una laguna que puede ser explicada por el peso que las variables organizacionales internas de los partidos tuvieron en la mayor parte de

1. Nos gustaría agradecer especialmente al Grupo Espacial ALACIP y, particularmente, a la Profa. Sonia Terrón por sus comentarios y sugerencias durante el último congreso de la asociación en Quito, así como a los evaluadores anónimos por sus importantes comentarios y constructivas sugerencias. También merece mención destacada el apoyo recibido del Centro de Estudios Latinoamericanos de la Universidad de Brown (EE.UU.), en particular a su director, el Prof. Richard Snyder, dado que ha sido en este centro en que parte de este artículo ha sido escrito. 
los trabajos recientes, principalmente cuando se lleva en cuenta la interacción con otras arenas de actuación de los partidos (la electoral y la del gobierno).

Otro factor relevante para el estado todavía incipiente de los estudios territoriales de los partidos y sistemas partidarios se justifica por el hecho de que sólo muy recientemente el avance en la tecnología de información y la expansión del uso de ordenadores personales han permitido de modo más extensivo la utilización de un volumen extenso de datos estadísticos y de sistemas de información geográfica. Este fenómeno resulta todavía más actual cuando se considera que sólo muy recientemente se han popularizado los métodos de análisis espacial en las ciencias sociales (Porter y Howell 2012; Goodchild y Janelle 2004).

Tal avance ha permitido la profusión de estudios sobre la territorialidad de los partidos y cómo sus estrategias espaciales han impactado en su éxito electoral en diversas escalas de disputa (Agnew 1996; Agnew 1997; Johnston y Pattie 2004; Calvo y Escolar 2003; Terron 2009). No obstante, poco ha sido dicho sobre el tema específico de cómo los partidos se organizan institucionalmente en el territorio, y menos sobre cómo este proceso se da en Brasil.

El objetivo del presente artículo consiste en investigar el caso brasileño empíricamente, en un intento de comprender cómo los principales partidos se han estructurado territorialmente desde fines de la década de 1980 hasta la actualidad. Para ello, se examinarán sus aspectos organizacionales desde una perspectiva tanto sistémica como espacial, considerando particularmente la distribución territorial de los afiliados y de los órganos de organización partidaria. ¿La distribución de los afiliados y la de la organización de los partidos presentan algún patrón espacial coherente? ¿Existe alguna relación clara entre estas dos variables?

En ese sentido, se busca investigar la relación entre distribución y cobertura territorial de los partidos en términos de organización y densidad de la afiliación y algunas características de la actuación de los partidos - como el número de candidatos y los votos obtenidos por cada afiliado- a nivel local. Para tal, se utilizarán los municipios brasileños como unidad de observación del comportamiento territorial de los partidos.

Dado el carácter fundamentalmente exploratorio de este estudio, un tercer objetivo planteado aquí consiste en formular algunas hipótesis sobre las relaciones causales entre organización partidaria, nivel de penetración y densidad de afiliación y las características del sistema partidario y el desempeño electoral a nivel local.

Este trabajo se encuentra dividido de la siguiente manera. En la próxima sección se desarrolla el argumento central y se discuten las categorías analíticas que fundamentarán el análisis de la organización de los partidos. En la tercera sección se buscará explorar empíricamente los patrones de distribución territorial de los datos de organización y afiliación de los partidos. En la cuarta sección se compararán los datos, por un lado, de organización y afiliación y, por otro, de candidaturas y votación a nivel local. Finalmente, el último apartado teje algunas consideraciones finales y formula algunas hipótesis sobre el perfil organizativo y sus consecuencias sobre el desempeño electoral de los partidos. 
MARIA DO SOCORRO SOUSA BRAGA, RODRIGO RODRIGUES-SILVEIRA Y TIAGO BORGES ORGANIZACIÓN, TERRITORIO Y SISTEMA PARTIDARIO: DIFUSIÓN TERRITORIAL DE LA ORGANIZACIÓN DE LOS PARTIDOS Y SUS POTENCIALES IMPACTOS SOBRE..

\section{ORGANIZACIÓN PARTIDARIA Y TERRITORIO: DIMENSIONES ANALÍTICAS}

Es posible estructurar la literatura sobre organización partidaria y sus consecuencias para el sistema partidario en dos líneas interpretativas. La primera se denomina begemónica, considera a los partidos como funcionales a las estrategias electorales de los actores individuales. La segunda, clásica, presenta los aspectos organizacionales como condicionantes y definidores del comportamiento de los partidos y candidatos en la arena de competencia electoral. Se trata de una clasificación que permite presentar diferencias de peso explicativo de elementos organizacionales en los fenómenos electorales, mostrando un poco cómo la ciencia política ha variado con relación al tema a lo largo del tiempo.

Para una parte significativa de la literatura, que ha sido producida a partir de la década de 1980, los partidos brasileños carecerían de una sólida estructura organizacional, al no construir cualquier arraigo social y control sobre sus miembros. Resulta importante ubicar el argumento en un contexto de gran desconfianza de las instituciones del país, revitalizadas durante el proceso de democratización. Sobre todo, tal actitud se manifiesta especialmente en relación a las reglas electorales: lista abierta, federalismo y sistema proporcional.

Este tipo de interpretación se encuentra tanto en trabajos temerosos en cuanto a la estabilidad de la democracia (Lamounier y Meneguelo 1986; Lamounier 1992), como en contribuciones más recientes que, aunque admitiendo cierta funcionalidad del sistema, terminaron centrándose en las patologías de la representación política brasileña (Mainwaring 2001; Kinzo 2004, 2005; Melo 2007).

La caracterización de los partidos políticos brasileños hecha por Scott Mainwaring es, quizás, la versión más extrema de ese argumento:

[los partidos] son máquinas electorales: controlan poco a los políticos; son más o menos disciplinados, desempeñan un papel secundario en las campañas; tienen relativamente poco control sobre las afiliaciones, sobre la acción y elección de los políticos. Los partidos brasileños se caracterizan por organizaciones flojas, que permiten que los políticos actúen con desconsideración a reglas y compromisos. Les falta cohesión; muchas veces son las disputas locales entre 'caciques', y no las grandes cuestiones políticas o ideológicas, las que determinan la afiliación a un partido (Mainwaring 1999: 220).

En este pasaje se observan algunas características básicas que tal literatura atribuye al sistema: personalismo en las candidaturas, baja disciplina, control local (y por tanto descoordinado) de las afiliaciones, debilidad institucional del centro y la ulterior ausencia de motivaciones programáticas o ideológicas en la acción de los partidos.

Dicho diagnóstico también se observa en trabajos que analizan el Partido de los Trabajadores (PT), resaltando su completa singularidad organizacional, una excepción en la realidad partidaria brasileña según tal literatura. Debido a sus especificidades en el surgimiento y en el arreglo institucional, el PT resulta normalmente presentado como una excepción en la «normalidad» brasileña, caracterizada por una fragilidad construida por políticos que desean fortalecer la reputación personal en detrimento 
MARIA DO SOCORRO SOUSA BRAGA, RODRIGO RODRIGUES-SILVEIRA Y TIAGO BORGES ORGANIZACIÓN, TERRITORIO Y SISTEMA PARTIDARIO: DIFUSIÓN TERRITORIAL

DE LA ORGANIZACIÓN DE LOS PARTIDOS Y SUS POTENCIALES IMPACTOS SOBRE..

de la partidaria. Como señala Meneguelo (1989: 36), «casi la totalidad de las organizaciones partidarias $[\ldots]$ carece de fuerte arraigo social en su formación, definiendo un perfil organizacional frágil».

Para tales estudios, la principal causa de esas fragilidades se originaría en las instituciones que regulan el sistema político brasileño. Las organizaciones partidarias débiles resultarían de estrategias de los políticos dentro de un conjunto específico de reglas, como, por ejemplo, el sistema proporcional, el presidencialismo y la lista abierta. Para conquistar cargos, en este ambiente institucional, los políticos moldearían los partidos de manera frágil, diseñando una estructura que permitiera autonomía tanto en campañas como en la actividad parlamentaria. Se pueden constatar semejanzas con el argumento de autores de la llamada «teoría de la elección racional» que sostienen que tanto el comportamiento partidario de los políticos (Cox 1987) y electores (Mayhew 1974), así como los dispositivos internos de un partido (Aldrich 1995, 2006), son el producto de estrategias dentro de un conjunto de instituciones electorales. Como señala John Aldrich,

El punto central aquí es que [...] los partidos políticos asumen la forma de instituciones por actores políticos, frecuentemente en el mismo marco temporal y por las acciones de los mismos personajes que modelan la legislación u otros resultados políticos. Existen, por tanto, instituciones no usualmente 'endógenas' , y, por eso, se debe tener en cuenta que instituciones partidarias (o al menos organizaciones) pueden cambiar con rapidez y facilidad más grande que virtualmente cualquier otra organización (Aldrich 2006: 557).

Sin embargo, dicha literatura confiere muy poca atención al hecho de que la misma debilidad desde el punto de vista de la estructura de la organización al interior de los partidos puede generar incentivos para la generación de comportamientos relativamente homogéneos desde una perspectiva territorial. John Agnew, en su ya consolidado estudio sobre la política italiana, destaca la política de alianzas estratégicas del partido Fuerza Italia de Berlusconi con partidos regionales como el principal factor de éxito en las elecciones nacionales. La asociación de una retórica nacional, una afiliación ideológica difusa ha permitido que el partido de Il Cavalieri pudiera construir la red de soporte político necesaria para el control del proceso electoral a nivel nacional (Agnew 1997) sobre otros partidos más ideologizados y con un enclave territorial más consolidado (Shin 2001).

En el caso de Brasil, la coherencia nacional de la actuación de los partidos se da por incentivos legales e institucionales, algo ya apuntado como de fundamental relevancia por algunos estudios sobre la nacionalización de los partidos en los países del este europeo (Tiemann 2012) o sobre los efectos del sistema electoral en la organización local de los partidos en Canadá (Carty y Eagles 1998) y en Suecia (Erlingsson 2008).

Distintamente de otros países federales de América Latina (como es el caso de Argentina o México), la legislación partidaria brasileña posee algunas características que generan fuertes incentivos para la coordinación entre niveles de gobierno y la nacionalización de los patrones de organización partidaria. En primer lugar, todas las elecciones para un mismo cargo subnacional (gobernador, diputados federales y estatales, 
alcalde o concejal) ocurren en un mismo momento. Los cargos en los que el distrito es el estado incluso se encuentran sincronizados con las elecciones nacionales (presidente). Las elecciones locales, aunque no sucedan al mismo tiempo que las estatales y nacionales, también son reguladas por ley nacional y ocurren de modo sincronizado en todo el país con dos años de diferencia de las estatales y federales. Todos esos elementos ayudan a que se observe cierto grado de coordinación política en el sistema (Carneiro y Almeida 2008).

Estos dos aspectos, regulación central y sincronización de elecciones, contrarrestan en gran medida las tendencias centrífugas desde una perspectiva territorial de los partidos en Brasil. Otra consecuencia de esta institucionalidad del sistema electoral deriva del hecho de que las elecciones subnacionales pasan a ser un recurso importante de poder e disputa por los partidos más grandes, cuya política de coaliciones o de expansión de la red local de influencia puede servir como importante recurso electoral en las elecciones nacionales (Limongi y Cortez 2010).

En ese sentido, al regular el sistema como un todo y para todas las elecciones (locales, estatales y federales), el conjunto de reglas e instituciones electorales brasileñas contrarrestan la formación de variaciones significativas en el perfil de organización de los partidos dentro del territorio brasileño.

De ese modo, una parte significativa de la literatura terminó por reducir la importancia de la interacción entre estructura organizativa descentralizada y sistema de regulación centralizado sobre los patrones de evolución del sistema de partidos brasileño. Como se argumenta en este trabajo, esto se debe a una excesiva preocupación en identificar los patrones de comportamiento de los políticos individuales y el poco esfuerzo sistemático en comprender los patrones de distribución de los partidos en el territorio y en diferentes cargos electivos.

Además, tales explicaciones van en contra de las contribuciones clásicas del inicio del siglo XX, encontradas en los estudios que inauguran la investigación de los partidos, como los trabajos de Ostrogorsky (1979), Weber (1993), Michels (1971) y Duverger (1951). El enfoque de tales textos clásicos será empleado aquí para interpretar los principales hallazgos con relación a la relación entre organización partidaria y características del sistema partidario.

La corriente clásica buscaba caracterizar las organizaciones según el grado de incorporación de sectores de la población al sistema político a partir de la extensión del sufragio, que ha propiciado un rápido aumento de la «inclusividad» en los sistemas políticos (Dahl 1971). De ese modo, desde la segunda mitad del siglo XIX, los partidos dejaron de tener contacto solamente con una pequeña parcela de la población y necesitaban ganar los «corazones y las mentes» de un público más amplio, incentivando la transformación de estructuras o conglomerados provisorios y frágiles, en general formados por notables, a favor de una organización sólida y permanente basada en cuadros².

2. Como apunta M. WEBER (1974: 74), «Los presupuestos de los partidos crecen rápidamente, pues el coste de las elecciones y el número de agitadores asalariados aumenta. No resulta posible conquistar un distrito más amplio ferozmente disputado sin gastar al menos veinte mil marcos [...]. 
MARIA DO SOCORRO SOUSA BRAGA, RODRIGO RODRIGUES-SILVEIRA Y TIAGO BORGES ORGANIZACIÓN, TERRITORIO Y SISTEMA PARTIDARIO: DIFUSIÓN TERRITORIAL

DE LA ORGANIZACIÓN DE LOS PARTIDOS Y SUS POTENCIALES IMPACTOS SOBRE..

Según Durverger (2004 [1951]), los arreglos institucionales iniciales de los partidos constituirían, por su parte, legados institucionales con fuerte influencia sobre su desempeño y posterior desarrollo. El autor argumenta que, «del mismo modo que los hombres conservan durante toda su vida la huella de su infancia, los partidos sufren profundamente la influencia de sus orígenes» (Duverger 2004: 15).

Este argumento resulta particularmente interesante para diferenciar los partidos en lo que se refiere a la relación entre territorio y organización. En particular, cabe determinar cuál es la relación entre la expansión o cobertura territorial y su capacidad de convertirse en partidos de masas. Para incorporar un número significativo de los electores en sus filas, un partido necesita, al menos, de una estructura que sea lo suficientemente capilar para captar adeptos y convertirlos en miembros del partido.

En ese sentido, el desempeño electoral sería profundamente influenciado por el modo con que se constituirían los partidos políticos. A pesar de algunas referencias breves hechas sobre el tema, tal tesis ha sido poco explorada por la literatura sobre partidos políticos, aunque el propio Duverger hubiese asumido que la extensión y cobertura de la organización partidaria

[A]lcanza una gran importancia; constituye el marco general de la actividad de los miembros, la forma impuesta a su solidaridad; determina los mecanismos de selección de los dirigentes y los poderes de éstos. Explica a menudo la fuerza y la eficacia de algunos partidos, la debilidad y la ineficacia de los demás [la itálica es nuestra] (Duverger 2004: 34).

Se pueden identificar tres ideas clave en los trabajos que tratan del desarrollo de los sistemas partidarios europeos, que señalan la existencia de una relación entre turbulencia organizativa y cambios en las estrategias electorales. A partir de factores exógenos (cambios en la estructura social, expansión de los medios de comunicación de masas) y endógenos (llegada de los partidos de masas al poder), los antiguos partidos de masas experimentaron profundas transformaciones en su estructura organizacional, tal como la reducción de la cantidad de afiliados, que ha alterado el modo de supervivencia y el posicionamiento del partido en la competencia electoral.

Este tema representa el centro de la contribución de Kirchheimer (1990), que vislumbra una estrecha relación entre estrategias electorales y las configuraciones internas de un partido político. La distribución de poder interna, el papel de los afiliados en las decisiones, el modo con que las campañas han pasado a hacerse han sido elementos de gran cambio en los partidos. Las tesis sobre el «partido cartel» de Mair y Katz (1992) también pueden ser pensadas a partir de tal perspectiva, que considera las transformaciones organizacionales (cada vez más dependientes del Estado) como causas del cambio de las estrategias en las élites políticas en el ámbito electoral a partir de la década de 1980.

La máquina del partido crece en importancia y, proporcionalmente, declina la influencia de los honoratiores». 
En la seminal obra de Panebianco (2005 [1988]), existe un enorme esfuerzo de investigación de los partidos a partir de las tesis organizacionales de Duverger. Muy cercano a lo que ya había afirmado tres décadas antes el autor francés, Panebianco sostiene la influencia del origen de los partidos en su desarrollo ulterior:

El modo por el cual se distribuyen las cartas y los resultados de las diversas partidas que se desarrollan en la fase genética de una organización y en los momentos inmediatamente siguientes continúan, en numerosos casos, condicionando la vida de la organización después de décadas (Panebianco 2005: 42).

Según Panebianco (2005), dichas elecciones iniciales influencian no sólo el montaje organizativo, sino el modo en que dicha estructura se relaciona con el mundo externo. Aunque lidie exclusivamente con desarrollos internos de los partidos, resulta posible trascender las afirmaciones de Panebianco y Duverger más allá de sus esfuerzos empíricos. El modo con que la organización partidaria se inserta en la competencia por votos también resulta influenciado por esos primeros pasos organizativos. De ese modo, comprender la actuación de un partido en el ambiente electoral requiere un estudio de las dinámicas (internas y externas) que condicionan los «incentivos» ofrecidos por los liderazgos a los electores y a los miembros del partido.

Sin embargo, distintamente de la perspectiva evolucionista defendida por Duverger (1951) y Michels (1971) con relación a los cambios en los partidos, Panebianco rechaza la idea de un desarrollo lineal de las organizaciones, exigiendo la consideración de otros elementos externos que puedan ejercer alguna influencia en la vida partidaria. Por consiguiente, para Panebianco (2005), no existe una vía única o predeterminada para el cambio de los partidos.

El supuesto defendido por este autor es que el modo de formación y consolidación de un partido (su modelo originario y las peculiaridades de su proceso de institucionalización), los tipos de presión que sufre en los ambientes que actúa y la manera con que dichas presiones afectan las relaciones de poder al interior de los partidos son cruciales para identificar cómo se ha dado el proceso de desarrollo de la estructura organizacional de un partido político.

Es justamente en ese punto que el elemento territorial de las organizaciones adquiere particular interés en la teoría de Panebianco (2005). Este autor argumenta que existen al menos tres modos típicos de ocupación del espacio nacional. El primero consiste en la penetración territorial, es decir, un «centro» controla y dirige la red organizacional de donde parte hacia la ocupación de regiones periféricas. El segundo corresponde a la difusión territorial, que sucede cuando las élites locales inician la estructuración del partido por sus regiones y solamente en un segundo momento conforman un centro nacional. En esos casos, las «baronías» tienden a poseer un peso significativo en las decisiones del partido. La tercera consiste en la combinación de ambas modalidades. Cada uno de esos aspectos organizacionales afecta de forma diferenciada la composición de la coalición dominante en cuanto al formato y la estructura de distribución del poder entre las varias instancias partidarias. 
MARIA DO SOCORRO SOUSA BRAGA, RODRIGO RODRIGUES-SILVEIRA Y TIAGO BORGES ORGANIZACIÓN, TERRITORIO Y SISTEMA PARTIDARIO: DIFUSIÓN TERRITORIAL

DE LA ORGANIZACIÓN DE LOS PARTIDOS Y SUS POTENCIALES IMPACTOS SOBRE..

\section{EVIDENCIAS DE LA DIFUSIÓN Y ORGANIZACIÓN TERRITORIAL DE LOS PARTIDOS BRASILEÑOS}

El primer paso en el análisis de la estructura organizativa de los partidos en Brasil consiste en llevar a cabo un conjunto de procedimientos básicos de descripción y exploración de su formato. Hasta el momento, pocos estudios se han dedicado a entender cómo ha evolucionado la difusión territorial y su relación con el nivel de afiliación de los partidos desde una perspectiva inclusiva.

Algunos trabajos muy interesantes han sido llevados a cabo para el caso del PT, partido considerado como excepción en el sistema brasileño y, por tanto, especialmente estudiado como tal (Samuels 1997; Mainwaring 2011; Meneguelo 1989). Uno de los más logrados es el trabajo de Amaral (2011) al revelar que el PT, al asumir el gobierno, no ha dejado de ser permeable a la participación de la sociedad civil y a la expansión de sus afiliados. Además, el autor destaca que sólo a partir de la primera década del siglo XXI ha sido capaz de extender su cobertura territorial a todo el país.

Además, el estudio de Amaral (2011) revela la importancia de dos indicadores para identificar el patrón general de evolución en la organización de los partidos brasileños desde la década de 1980. El primero de ellos corresponde a la cobertura o grado de penetración territorial. Se conforma por la proporción del total de municipios del país en que un determinado partido posee afiliados u organización propia. El segundo corresponde a la densidad de la afiliación, se expresa en el número de afiliados por cada mil electores. Este último indicador mide no sólo si el partido se encuentra presente en una localidad, sino también la importancia relativa de cada municipio en términos de capacidad de movilización.

La interacción entre estos dos indicadores conforma un espacio de propiedades que permite encuadrar la evolución de los partidos según tres trayectorias posibles (Figura I). Cada trayectoria sería explicada por un formato específico asumido por la asociación entre cobertura territorial y densidad de la afiliación en el tiempo.

La primera de ellas, simétrica o lineal, consistiría en la relación directa en la que el aumento de $\mathrm{X}$ en cobertura territorial de los partidos representaría una proporción idéntica en la densidad de la afiliación. Esta relación también puede ser denominada lineal, dado que sería representada por una recta perfectamente ajustada por un modelo de regresión lineal simple. Por tanto, los procesos de nacionalización de los partidos y su conversión a partidos de masas estarían en conexión directa. Sin la primera no se observa la segunda y viceversa.

Las dos trayectorias siguientes, por su parte, consideran que la evolución de la relación entre expansión territorial y partidos de masas no resulta directa o lineal. Más bien, dicha relación se establece a partir de dos etapas principales que varían según la precedencia de cada una de las dimensiones involucradas: la cobertura o la densidad de afiliación.

La segunda, la trayectoria exponencial, correspondería a un aumento inicial de la cobertura territorial (o un punto de partida en que los partidos ya nacen con niveles relativamente altos de cobertura territorial) casi en la misma proporción del aumento 
de los afiliados y, sólo en un momento posterior, presentan resultados exponenciales en la progresión de la densidad de afiliación ${ }^{3}$.

\section{FIGURA I}

\section{TRAYECTORIAS HIPOTÉTICAS DE LA RELACIÓN ENTRE DIFUSIÓN TERRITORIAL} DE LOS PARTIDOS Y DENSIDAD DE LA AFILIACIÓN

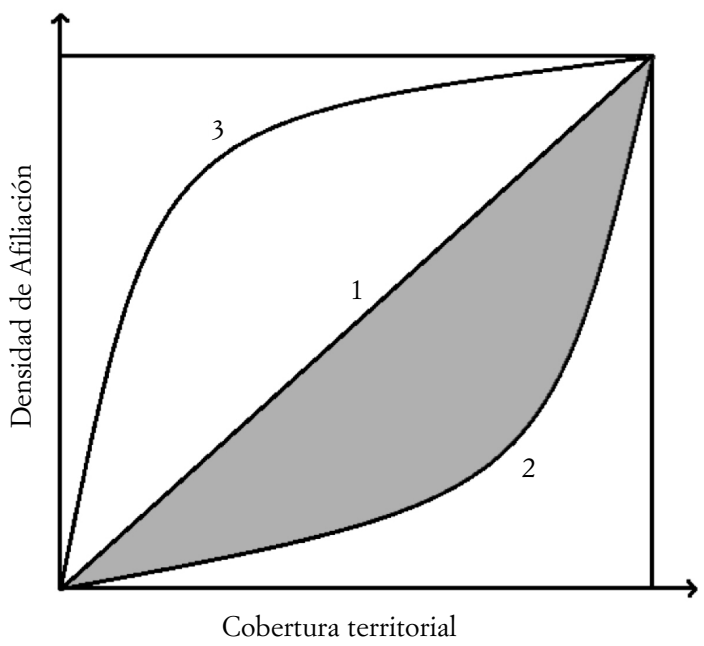

1. Simetría perfecta

2. Expansión territorial seguida de aumento de afiliación

3. Aumento de la afiliación seguido de expansión territorial

Fuente: Elaboración propia.

Quizás la principal consecuencia teórica de esta trayectoria se deriva del hecho de que sería necesario un nivel mínimo o umbral (threshold) de cobertura territorial para la expansión o masificación de los partidos. En ese sentido, los partidos deberían alcanzar un mínimo de nacionalización de su estructura organizacional antes de obtener el estatuto de partido moderno de masas o, de modo menos enfático, niveles más altos de densidad de afiliación que le permitieran competir a nivel nacional.

La tercera trayectoria, logarítmica (o exponencial inversa), consiste en el caso contrario a la anterior. En este caso, el aumento de la afiliación constituiría la condición previa o precedente para la nacionalización o penetración territorial de los partidos. Una parte importante de los estudios sobre el PT en Brasil explican la evolución del partido en estos términos, es decir, primero una concentración de una base popular

3. Se considera aquí que la cobertura territorial es condición para explicar la expansión de la afiliación, por esa razón se la ubica en el eje $\mathrm{x}$ del plano que explica las trayectorias típicas y se la denomina exponencial. En el caso de que se asumiese la causalidad reversa, es decir, el aumento de la afiliación explica la cobertura territorial, esta trayectoria sería logarítmica. Sin embargo, como se podrá ver más adelante, la evidencia empírica entre 1988 y 2011 suministra importantes evidencia a favor de la precedencia de la cobertura territorial sobre la expansión de la densidad de afiliación en el sistema político brasileño. 
del partido en un conjunto pequeño de municipios, pero formado mayoritariamente por grandes ciudades y, luego, una expansión territorial del partido y su efectiva nacionalización en la década de 2000.

Finalmente, resulta importante explicar qué representa teóricamente el área gris, denominada aquí área de divergencia, de la Figura I. Esta área representa la distancia total que un partido, en su proceso de desarrollo institucional, se ha alejado de la condición ideal o lineal -formada por el supuesto de que a mayor cobertura territorial tanto mayor su densidad de afiliación o masificación-. En ese sentido, partidos cuya evolución ha sido en etapas -es decir, con un primer movimiento de expansión territorial seguido luego de una expansión exponencial de los afiliados- tenderían a presentar un área de divergencia más extensa que otros en que la relación resulta más lineal o simétrica.

Antes de pasar al análisis de la relación entre las dos dimensiones, resulta interesante examinar la evolución de cada uno de los indicadores con el objetivo de identificar patrones de evolución a lo largo del período comprendido entre 1989 -año de la primera elección directa a presidente- y 2010, en que ha sido lleva a cabo la última elección nacional.

La Tabla I suministra las informaciones sobre la evolución de las afiliaciones de 1989 a 2010 para los partidos brasileños. El primer dato relevante se encuentra en el hecho de que todos los partidos han aumentado la densidad de afiliación, medida por el número de afiliados por mil electores. En 1989, solamente el Partido del Movimiento Democrático Brasileño (РMDB) presentaba una proporción de afiliados superior a 10 por cada mil y era seguido desde muy lejos por los demás partidos. Al final del período, se observa la multiplicación del número de afiliados por mil habitantes, lo que constituye una sólida evidencia de una mayor densidad en la penetración social de los partidos y del sistema partidario brasileño de forma más general.

TABLA I

NÚMERO DE AFILIADOS POR MIL ELECTORES (1989-2010)

\begin{tabular}{l|c|c|c|c|c|c}
\hline \multicolumn{2}{l}{1989} & 1994 & 1998 & 2002 & 2006 & 2010 \\
\hline PMDB & 11.36 & 12.84 & 14.44 & 16.30 & 18.20 & 18.49 \\
\hline PT & 2.83 & 3.70 & 5.25 & 7.33 & 10.23 & 11.97 \\
\hline PSDB & 1.18 & 3.74 & 6.38 & 8.38 & 10.30 & 11.14 \\
\hline PP & 2.61 & 5.35 & 7.95 & 9.33 & 9.96 & 10.03 \\
\hline PTB & 2.60 & 4.03 & 6.24 & 8.09 & 9.18 & 9.58 \\
\hline PDT & 3.97 & 5.75 & 6.80 & 7.63 & 8.80 & 9.47 \\
\hline DEM & 3.07 & 4.00 & 5.73 & 7.92 & 8.87 & 9.06 \\
\hline Otros & 0.16 & 0.48 & 0.40 & 0.62 & 0.78 & 1.16 \\
\hline
\end{tabular}

Fuente: Elaboración propia a partir de datos del TSE. 
Otro aspecto que merece ser destacado es que el ritmo de crecimiento ha sido más rápido durante la década de 1990 que en la siguiente, aunque el movimiento de expansión no se ha interrumpido durante todo el período analizado. Si se comparan los datos para 1989 y 2002, resulta que los partidos han en media triplicado su densidad de afiliación. El caso más extremo se encuentra en el Partido de la Social Democracia Brasileña (PSDB) que ha aumentado en 7.1 veces el número de sus afiliados por grupo de mil electores. Entre 2002 y 2010 este movimiento de expansión ha seguido su curso, pero con niveles menores que representan en media un $33 \%$ de incremento en el período.

Un comportamiento semejante puede observarse con relación a la cobertura territorial de los partidos en términos de afiliación (Tabla II). La tendencia general, como se puede constatar, es la del aumento progresivo de la afiliación en todos los partidos durante el período entre 1989 y 2010. Como en el caso de la densidad de afiliación, la cobertura territorial también ha aumentado de forma significativa y para todos los partidos.

TABLA II

COBERTURA TERRITORIAL DE LA AFILIACIÓN DE LOS PARTIDOS (1989-2010)

\begin{tabular}{l|c|c|c|c|c|c}
\hline & 1989 & 1994 & 1998 & 2002 & 2006 & 2010 \\
\hline DEM & 0.727 & 0.810 & 0.886 & 0.928 & 0.938 & 0.942 \\
\hline PDT & 0.603 & 0.724 & 0.824 & 0.875 & 0.928 & 0.952 \\
\hline PMDB & 0.917 & 0.950 & 0.983 & 0.993 & 0.998 & 0.999 \\
\hline PP & 0.617 & 0.789 & 0.903 & 0.942 & 0.975 & 0.980 \\
\hline PSDB & 0.371 & 0.734 & 0.911 & 0.950 & 0.979 & 0.986 \\
\hline PT & 0.598 & 0.712 & 0.814 & 0.905 & 0.980 & 0.990 \\
\hline PTB & 0.523 & 0.696 & 0.845 & 0.920 & 0.971 & 0.975 \\
\hline Otros & 0.025 & 0.062 & 0.168 & 0.243 & 0.328 & 0.433 \\
\hline
\end{tabular}

Fuente: Elaboración propia a partir de datos del TSE.

Nota: La última columna representa la proporción de municipios en 2011 en que el partido poseía algún tipo de organización partidaria vigente (directorio o comisión provisoria).

La principal diferencia, no obstante, se encuentra entre los partidos considerados grandes en términos de afiliación y los demás partidos pequeños. Mientras los primeros ya iniciaron el período (1989) con niveles relativamente elevados de cobertura territorial (con la excepción del PSDB), los últimos apenas podían organizarse en pocos municipios.

Al dividir la progresión en décadas también se observa que la principal expansión ha sido llevada a cabo durante la década de 1990, que ha correspondido a una media del $59 \%$ para los grandes partidos y 9.7 veces con relación a los pequeños. La segunda sección (2002-2010) ha representado una expansión pequeña de los grandes (media del $5 \%$ ), en gran medida justificada por la ya alta cobertura territorial alcanzada hasta 2002. Los pequeños partidos, no obstante, siguieron aumentando su cobertura territorial en 
MARIA DO SOCORRO SOUSA BRAGA, RODRIGO RODRIGUES-SILVEIRA Y TIAGO BORGES ORGANIZACIÓN, TERRITORIO Y SISTEMA PARTIDARIO: DIFUSIÓN TERRITORIAL

DE LA ORGANIZACIÓN DE LOS PARTIDOS Y SUS POTENCIALES IMPACTOS SOBRE...

un $78 \%$, llevando a un movimiento de convergencia general del sistema (aunque existan diferencias importantes como se argumentará más abajo).

El examen de estos dos indicadores revela una tendencia clara de consolidación de los partidos tanto en términos de su penetración social como en cuanto a la cobertura territorial. Tal tendencia es sistemática por dos razones: (a) se observa para todos los partidos; y (b) resulta progresiva en el tiempo, es decir, no presenta regresión o movimientos de reversión frente al punto inicial (1989).

No obstante, estas tablas muestran muy poco sobre el formato de la relación entre esas dos dimensiones: densidad de afiliación y expansión territorial de los partidos. Como se podrá ver en la Figura II, existen dos trayectorias distintas para los partidos grandes y los pequeños o medianos ${ }^{4}$. Los partidos grandes se caracterizan por el hecho de que: (a) ya poseían gran cobertura territorial en el momento de la redemocratización (PMDB); $\mathrm{o}$ (b) ganaron rápidamente terreno en los primeros años (PT y PSDB) y presentan un formato de evolución exponencial. En los primeros años expandieron su cobertura territorial y, luego, utilizaron dichas bases como puente para consolidar y ampliar sus bases electorales y de militancia local.

\section{FIGURA II}

RELACIÓN ENTRE COBERTURA TERRITORIAL Y AFILIADOS POR MIL ELECTORES EN LOS MUNICIPIOS BRASILEÑOS ENTRE 1988 Y 2011 (PARTIDO-AÑO)
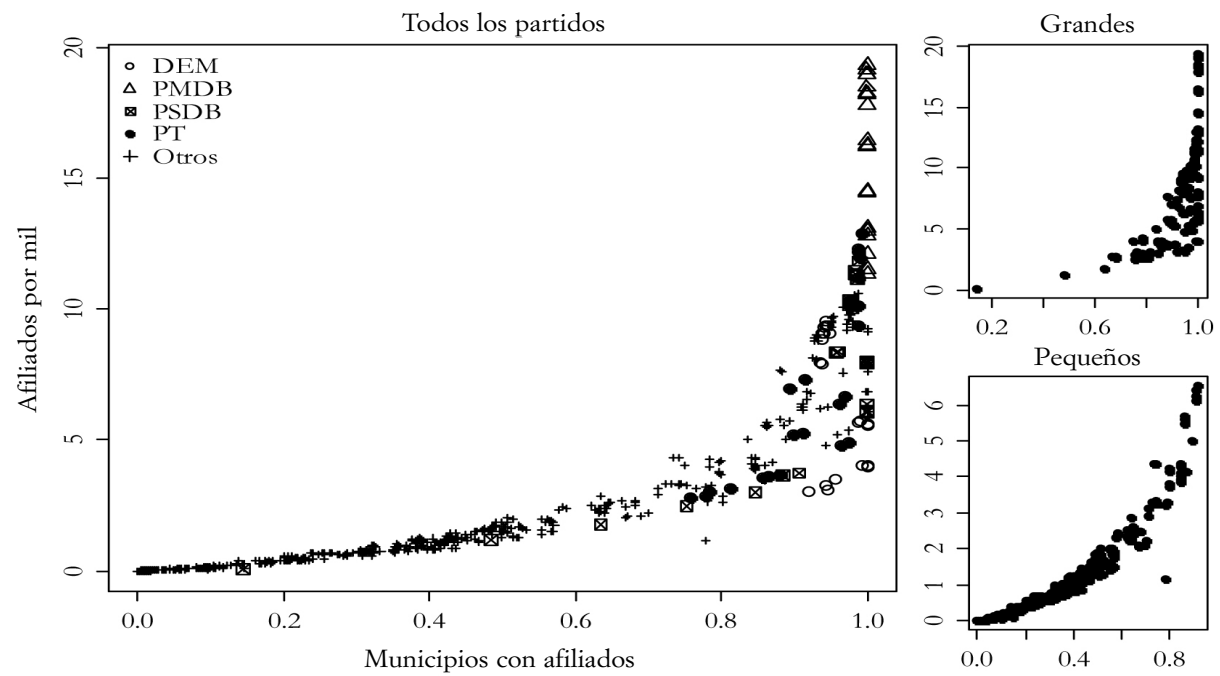

Fuente: Elaboración propia a partir de datos del TSE (1988-2011).

4. Para evitar equívocos de interpretación de los resultados, cabe destacar que, en el presente trabajo, la diferencia entre partidos grandes, medianos y pequeños se hace con relación al número de afiliados y no considerando su representatividad en el Congreso nacional. En el caso de que su representatividad legislativa nacional fuese considerada, algunos de los partidos considerados aquí como grandes tendrían que ser reclasificados como medianos como es el caso del PDT, PP o PTB. 
MARIA DO SOCORRO SOUSA BRAGA, RODRIGO RODRIGUES-SILVEIRA Y TIAGO BORGES ORGANIZACIÓN, TERRITORIO Y SISTEMA PARTIDARIO: DIFUSIÓN TERRITORIAL DE LA ORGANIZACIÓN DE LOS PARTIDOS Y SUS POTENCIALES IMPACTOS SOBRE..

Los partidos pequeños (representados en negro en el gráfico y en el cuadro inferior a la derecha) presentaron un comportamiento mucho más lineal en su evolución. Como se puede observar en la Figura II, a lo largo del período han sido capaces de expandir su cobertura territorial en una ratio bastante pequeña y en una progresión lineal con relación a la afiliación.

Aunque la relación no haya sido $1 \mathrm{x} 1$, entre los dos indicadores, su comportamiento no ha cambiado en un momento específico del tiempo, como lo hizo en el caso de los grandes partidos. Los casos que más se asemejan a un formato más cercano al de los partidos grandes son los partidos medios (PSB, PPS, PR) que han aumentado su cobertura territorial y que quizás puedan conformar un tercer grupo, pero que, de cualquier modo, presentan el mismo comportamiento identificado por el modelo descrito en la Figura I.

Sorprendentemente, ningún caso ha sido identificado para la tercera trayectoria (logarítmica), es decir, no ha habido ningún partido cuya trayectoria de evolución institucional se haya llevado a cabo por medio de un proceso de masificación de los afiliados y, luego, su interiorización o de que hayan partido de un nivel alto de afiliación para sólo después expandir su cobertura territorial. En gran medida eso puede justificarse por el hecho de que se ha medido la evolución de los afiliados en términos relativos, es decir, controlándola por el total de electores. Sin embargo, el argumento teórico de que la expansión territorial sería una condición para la posterior masificación parece ser más fuerte.

Sin embargo, la inspección visual de los casos no constituye evidencia empírica suficiente para establecer tal relación de modo más convincente. Una alternativa para medir las diferencias entre las trayectorias de los partidos sería intentar medir el tamaño del área de divergencia de cada partido frente a la situación de simetría perfecta.

Una solución inicial que permite evaluar la hipótesis de diferencias cualitativas entre partidos pequeños/medianos y grandes en el sistema político brasileño es considerar el tamaño del área de divergencia con relación a la situación lineal. Este procedimiento puede llevarse a cabo por la suma de los cuadrados de los residuos de una regresión lineal simple en que la variable dependiente es el número de afiliados por mil electores y la independiente corresponde a la cobertura territorial de los partidos.

Este indicador aproximado brinda más una evidencia de trayectorias distintas entre los grandes y pequeños/medianos partidos. Como se puede observar en la Tabla III, los cuatro partidos más grandes poseen residuos muy superiores a los demás. En particular de los partidos pequeños.

Otro elemento de especial interés en los resultados observados es que estos indican tanto el PSDB como el PT como los partidos en que la trayectoria exponencial ha sido la más acentuada. Estos datos se encuentran en completa consonancia con los estudios recientes que apuntan hacia una hegemonía de esos dos partidos en las coaliciones para las elecciones presidenciales y sobre la importancia de su estrategia territorial como foco de su éxito electoral a nivel nacional.

Desde el punto de vista de las trayectorias, los datos de la Tabla III sugieren la existencia de un tercer grupo compuesto por algunos de los partidos más grandes (PDT, 
PP Y PTB) y por otros intermedios (PPS, PR Y PSB), que efectivamente se sitúan en un punto intermedio, es decir, que han alcanzado un nivel relativamente alto de cobertura territorial de la afiliación y que empiezan a expandir rápidamente la densidad de sus afiliados.

La cuestión planteada por dicha interpretación sería: ¿estarán tales partidos en un proceso de transición a un modelo de partidos nacionales de masas o constituyen una categoría intermedia de carácter más institucionalizado? Es decir, ¿hasta qué punto la posición de tales partidos es temporal o más fija en el tiempo? ¿El aumento de la afiliación en los partidos más grandes constituiría alguna limitación a estos partidos intermedios?

Más que dar una respuesta definitiva a esta cuestión, lo que se desea destacar aquí es la utilidad del empleo del modelo de análisis propuesto en la Figura I para entender la evolución reciente de los partidos políticos brasileños en términos de su cobertura territorial y aumento de su penetración en el electorado.

\section{TABLA III}

RESIDUOS EN LA DENSIDAD DE AFILIADOS (1989-2011)

\begin{tabular}{l|c}
\multicolumn{2}{c}{ Grandes partidos } \\
\hline \multicolumn{1}{c}{ Partido } & Residuos \\
\hline PSDB & 66.08 \\
\hline PT & 29.88 \\
\hline PMDB & 25.86 \\
\hline DEM & 13.57 \\
\hline PTB & 6.97 \\
\hline PP & 3.14 \\
\hline PDT & 2.41 \\
\hline
\end{tabular}

\begin{tabular}{l|c}
\multicolumn{2}{c}{ Medianos y pequeños } \\
\hline \multicolumn{1}{c}{ Partido } & Residuos \\
\hline PSB & 2.23 \\
\hline PR & 1.72 \\
\hline PPS & 1.49 \\
\hline PSC & 0.45 \\
\hline PV & 0.45 \\
\hline PC do B & 0.30 \\
\hline Otros & $<0.30$ \\
\hline
\end{tabular}

Fuente: TSE (1989-2010).

Lo que se desea reiterar en esta parte del trabajo es que tanto la expansión de la cobertura territorial como la tendencia al aumento de la afiliación corresponden a características generales del sistema partidario brasileño desde la década de 1980. No obstante, se observan dos patrones distintos de expansión: la penetración territorial y el aumento de la densidad de las afiliaciones.

La penetración territorial consiste en el aumento de los municipios en que un partido posee afiliados u organización. Esfuerzos en el sentido de mayor penetración territorial parecen aumentar la cobertura geográfica de actuación de un partido y, por tanto, establecer bases mínimas para su actuación en un territorio más amplio.

Esta estrategia es la que los pequeños partidos han adoptado. Incapaces de convertirse en partidos de masas, han optado por aumentar su cobertura territorial como condición previa para el aumento de su penetración social y una mayor densidad de las afiliaciones. Sin embargo, como se verá más adelante, lo harán por medio de 
organizaciones de carácter provisional e institucionalmente frágil, mientras que los principales partidos optan por mayor institucionalidad en su organización.

El aumento de la densidad de las afiliaciones constituye una característica típica de los grandes partidos (DEM, PDT, PMDB, PP, PSDB, PT y PTB), aunque también se observe en menor grado en los demás. Los primeros, al alcanzar determinado nivel de cobertura territorial, aumentan significativa y exponencialmente la proporción de afiliados en el total del electorado.

Por tanto, la existencia de patrones sistemáticos tanto para la evolución de los grandes y pequeños partidos cuestiona el sentido común establecido sobre el tema que defiende una desorganización estructural de los partidos. Aunque este argumento pueda ser válido para la organización interna de algunos partidos, se observa que existen otros elementos institucionales en juego que generan un patrón visiblemente estable cuando se considera el sistema como un todo 5 .

Entre tales aspectos institucionales, se destaca la relativa preservación de las reglas del juego electoral, que ha conferido previsibilidad al sistema político como un todo. Otro elemento crucial se refiere al papel estructurador de las elecciones presidenciales, ampliado con la vinculación de los comicios nacionales y estatales tanto para el Ejecutivo como para el Legislativo a partir de 1994.

De acuerdo con Carey y Shugart (1992) la simultaneidad de tales elecciones en contextos presidenciales, como el brasileño, tiende a contribuir a la reducción de la fragmentación partidaria y, por consiguiente, a concentrar el sistema alrededor de los partidos más relevantes. Esto sucedería como consecuencia de las estrategias de coordinación electoral desarrolladas, de un lado, por los liderazgos partidarios y, de otro, por los electores.

Además, la ley electoral exige que los partidos cuenten con una base organizacional en todo el país. Dicha determinación, al establecer que los partidos deban organizarse formalmente en al menos $1 / 3$ de los estados brasileños para poder participar del proceso electoral, estimula la competencia entre partidos de perfil ideológico semejante y la cooperación en coaliciones electorales heterogéneas. El objetivo de tal estrategia sería el de ampliar (en el caso de los partidos pequeños) o de mantener (en los grandes) su base nacional. Aspecto este que también ha ayudado en la supervivencia de partidos pequeños y medianos.

Finalmente, otro elemento institucional importante que ha contribuido a la mayor homogeneidad territorial del sistema de partidos brasileño (y su relativa estabilidad) se encuentra relacionado con el dispositivo de la reelección. A partir de 1997, todos los políticos elegidos para cargos ejecutivos pasaron a tener el derecho a presentarse

5. Cabe destacar un matiz importante, partidos como PT, PMDB, PSDB, PTB, PDT poseen una organización intrapartidaria consistente. En algunos casos se observan procesos decisorios más centralizados, mientras que en otros descentralizados. Por otra parte, DEM, PP y PPS (entre otros) no disponen de tal coherencia organizativa interna. Como se verá más adelante, los datos sobre el tipo de órgano partidario (directorio vs. comisiones provisionales) pueden dejar clara tal diferencia entre la «calidad» de la organización de tales partidos. 
nuevamente a las elecciones. La experiencia administrativa bien evaluada por los electores también se ha convertido, por tanto, en una estrategia territorial de los partidos que han visto las reelecciones como una posibilidad de la consolidación de los partidos en los tres niveles de gobierno.

En ese sentido, parece haber un proceso similar al que Panebianco (2005) denomina penetración territorial. Sin embargo, con una diferencia fundamental. Mientras que el autor atribuye la iniciativa de la penetración territorial predominantemente a las élites que se encuentran en el centro del partido, el caso brasileño parece demostrar que las reglas institucionales externas también desempeñan un papel decisivo para explicar el fenómeno de similitud en el patrón de expansión territorial y de afiliados de los partidos.

Como ha sido mencionado, la existencia de reglas nacionales relativas a la afiliación, el mantenimiento del registro de los afiliados en una misma organización electoral $^{6}$, la sincronía nacional de las elecciones de un mismo tipo constituyen elementos centrales que justifican el comportamiento sistemático de los partidos en términos de su patrón de organización y expansión territorial.

Estos elementos también explicarían el hecho de que, aunque internamente algunos partidos puedan ser fragmentarios y desorganizados, el sistema de partidos como un todo posee mecanismos de autorregulación que incentivan la adopción de un comportamiento común y sistemático.

Como sería de esperar, también es estrecha la relación entre la cobertura territorial de la afiliación y de la organización de los partidos. Como se puede observar en la Figura III, para todos los partidos, existe una relación casi que perfectamente lineal entre la proporción de municipios en que un partido posee al menos un afiliado y el número de localidades en que existe un directorio u otro tipo de organización partidaria de carácter formal.

Infelizmente, los datos disponibles para los órganos partidarios a nivel local no permiten reconstruir la trayectoria temporal de la evolución de la organización. Estas informaciones permitirían averiguar también cuál sería el tiempo necesario para que la expansión territorial de la afiliación se convierta en algún tipo de organización de carácter más formal y estable.

De cualquier modo, lo que se verifica para la actualidad es la casi completa correspondencia entre afiliación y organización. La calidad de tales instituciones y su funcionamiento no están aquí en cuestión. Puede haber una enorme variación en ese aspecto y es algo que los datos disponibles públicamente no permiten evaluar de modo más extensivo. Sin embargo, una vez más cabe destacar el hecho de la enorme sistematicidad del comportamiento de los partidos en cuanto al modo de su organización e institucionalización y en particular su relación con el territorio.

6. Cabe resaltar que, aunque los afiliados deban registrarse en sus municipios de residencia y son los partidos los que deciden las reglas por las cuales cada ciudadano puede afiliarse al partido, el solo hecho de que exista un registro nacional de afiliados, disponible públicamente en el Tribunal Superior Electoral, constituye una evidencia adicional de cierta capacidad de control, regulación y supervisión a nivel central. 
Algunas evidencias adicionales sobre la extensión territorial y la naturaleza más o menos estable de la organización se pueden encontrar en la Tabla IV. Como se puede observar, esta tabla indica, del total de organizaciones (una en cada municipio), cuántas de ellas son directorios partidarios, cuántas corresponden a comisiones provisorias, el porcentaje de directorios en el total y el porcentaje de municipios en que cada partido posee algún tipo de organización propia.

\section{FIGURA III}

COBERTURA TERRITORIAL: ORGANISMOS PARTIDARIOS VS. AFILIADOS (2011)

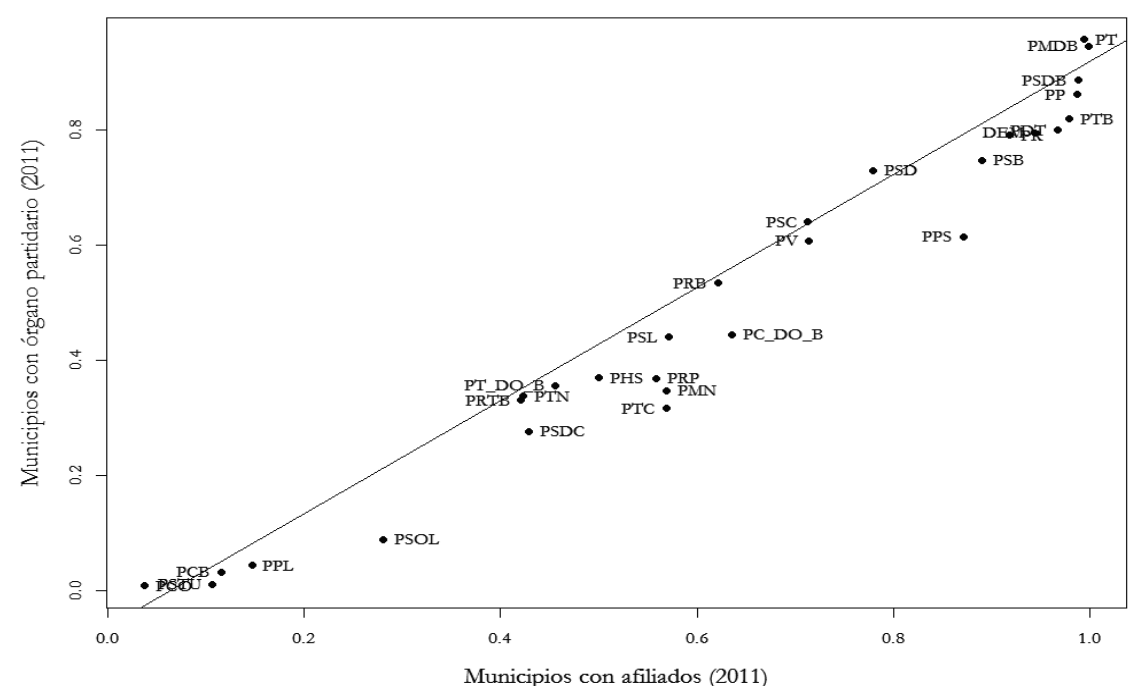

Fuente: Elaboración propia a partir de datos del TSE (2011).

Los directorios partidarios son unidades organizativas más complejas que las comisiones provisorias, pues se conforman por un número más elevado de miembros (variando según el partido) y exigen la realización de una convención municipal para su homologación. Las comisiones provisorias, a su vez, se instituyen por iniciativa de la dirección estatal del partido y poseen solamente una corta duración (90 días, al final de los cuales resulta necesaria una convención para homologarla como un directorio).

En ese sentido, la predominancia de los directorios sobre las comisiones provisorias, particularmente en el PT, PMDB y en menor porcentaje en el PSDB, y en los partidos menores de izquierda -como, por ejemplo, el PC do B- constituye el resultado de exigencias estatutarias restrictivas, pero también más duraderas y del control sistemático y democrático de los miembros, que obligan a la realización de convenciones municipales, fortaleciendo los órganos decisorios del partido a nivel local.

Además, en los directorios, se exige una mayor participación activa de los afiliados tanto de aquellos que solamente participan parte de las elecciones internas cada 2 años, 
MARIA DO SOCORRO SOUSA BRAGA, RODRIGO RODRIGUES-SILVEIRA Y TIAGO BORGES ORGANIZACIÓN, TERRITORIO Y SISTEMA PARTIDARIO: DIFUSIÓN TERRITORIAL

DE LA ORGANIZACIÓN DE LOS PARTIDOS Y SUS POTENCIALES IMPACTOS SOBRE..

como de los que deberán dirigir la organización, siendo algunos de ellos profesionales y recibiendo una remuneración por desarrollar dichas tareas organizativas. En ese sentido, los directorios constituyen el tipo más institucionalizado y formalmente democrático de organismo partidario en el sistema político brasileño.

En el caso de las comisiones provisorias - como sucede en los casos de DEM, PP, PTB, PDT y de la mayor parte de los pequeños partidos de derecha- los liderazgos partidarios intervienen cuando quieren y desplazan o mantienen en los cargos directivos locales aquellos afiliados que se encuentran más de acuerdo con sus líneas o conveniencias políticas. Esta estrategia fortalece una estructura de partidos de «barones» en la que figuras nacionales o regionales controlan el partido desde «arriba».

TABLA IV

INDICADORES DE LA ORGANIZACIÓN TERRITORIAL DE LOS PARTIDOS (2011)

\begin{tabular}{l|c|c|c|c|c}
\hline \multicolumn{1}{c|}{ Partido } & Total & Directorio & Com. Prov. $^{*}$ & \% dir*** & \% municipios \\
\hline PT & 5325 & 4221 & 1104 & 79.3 & 95.7 \\
\hline PMDB & 5262 & 3454 & 1808 & 65.6 & 94.5 \\
\hline PSDB & 4930 & 2395 & 2535 & 48.6 & 88.6 \\
\hline PP & 4791 & 1015 & 3776 & 21.2 & 86.1 \\
\hline PTB & 4561 & 27 & 4534 & 0.6 & 81.9 \\
\hline DEM & 4479 & 1081 & 3398 & 24.1 & 80.5 \\
\hline PDT & 4447 & 890 & 3557 & 20.0 & 79.9 \\
\hline PR & 4395 & 38 & 4357 & 0.9 & 79.0 \\
\hline PSB & 4160 & 473 & 3687 & 11.4 & 74.7 \\
\hline PSD & 4060 & 285 & 3775 & 7.0 & 72.9 \\
\hline PSC & 3563 & 65 & 3498 & 1.8 & 64.0 \\
\hline PPS & 3420 & 496 & 2924 & 14.5 & 61.4 \\
\hline PV & 3376 & 48 & 3328 & 1.4 & 60.7 \\
\hline PRB & 2975 & 6 & 2969 & 0.2 & 53.4 \\
\hline PSL & 2449 & 234 & 2215 & 9.6 & 44.0 \\
\hline PC do B & 2415 & 802 & 1613 & 33.2 & 43.4 \\
\hline PHS & 2055 & 350 & 1705 & 17.0 & 36.9 \\
\hline PRP & 2047 & 73 & 1974 & 3.6 & 36.8 \\
\hline PT do B & 1982 & 197 & 1785 & 9.9 & 35.6 \\
\hline PMN & 1930 & 49 & 1881 & 2.5 & 34.7 \\
\hline PTN & 1876 & 21 & 1855 & 1.1 & 33.7 \\
\hline PRTB & 1836 & 11 & 1825 & 0.6 & 33.0 \\
\hline PTC & 1761 & 35 & 1726 & 2.0 & 31.6 \\
\hline PSDC & 1535 & 92 & 1443 & 6.0 & 27.6 \\
\hline PSOL & 491 & 109 & 382 & 22.2 & 8.8 \\
\hline PCB & 177 & 9 & 168 & 5.1 & 3.2 \\
\hline PSTU & 63 & 21 & 42 & 33.3 & 1.1 \\
\hline PCO & 46 & 16 & 30 & 34.8 & 0.8 \\
\hline & & & & & \\
\hline
\end{tabular}

Fuente: Elaboración propia a partir de datos del TSE (2011).

* Número de comisiones provisorias.

** Porcentaje de directorios en el total de organismos partidarios a nivel local. 
Los datos de la Tabla IV confirman que el PT, seguido por el PMDB, constituyen los partidos con las estructuras organizacionales más sólidas. En particular, se destaca el hecho de que más del $50 \%$ de las instituciones organizativas de estos dos partidos se conforman por directorios. El PSDB se encuentra en el límite, con un porcentaje del $48,6 \%$.

Otro elemento que merece ser destacado es el carácter ideológico asociado a mayor organización. Los pequeños partidos de izquierda (PC do B, PSOL, PCO y PSTU) tienden a tener menor cobertura territorial general, pero, a diferencia de los demás pequeños partidos, optan por institucionalizar su acción por medio de la creación de directorios. Todos estos partidos presentan más del $20 \%$ de sus organizaciones como directorios y no como comisiones provisorias.

Los partidos de derecha se revelan mucho menos organizados en ese sentido. En su mayor parte, las organizaciones se constituyen por comisiones provisorias y el espacio de los directorios es muy reducido y se restringe solamente a las ciudades consideradas clave por su población o importancia política para el partido. El hecho que más llama la atención es que la baja incidencia de directorios es común para grandes, medianos y pequeños partidos de la derecha. El caso extremo es el del PTB, que es uno de los más extensos en cobertura territorial de la organización (4561), pero con solamente 27 municipios con directorios (el $0.6 \%$ del total).

\section{Perfil organizativo DE los PRINCIPAles Partidos A NiVEL LOCAL}

Una vez llevado a cabo el análisis exploratorio del comportamiento territorial de los partidos a nivel nacional, el propósito de esta parte del trabajo consiste en analizar los perfiles de afiliación y organización territorial de los partidos desde una perspectiva más desagregada. El objetivo es evaluar cómo afiliación y organización se distribuyen a nivel local, identificar potenciales patrones espaciales y averiguar su relación con otros elementos de interés como las candidaturas o votos. Por esta razón, se utilizarán los municipios como unidades de observación para investigar los patrones espaciales en los niveles de afiliación, organismos partidarios y candidaturas.

En particular, se enfatizará el análisis de los datos de afiliación y organización y su impacto sobre los votos y el desempeño de los candidatos a diputado federal. La elección de diputados federales se justifica con base en el hecho de que es un cargo nacional, pero disputado regionalmente (en los estados) y cada partido puede presentar más de un candidato, dado que los distritos son plurinominales (de 8 a 70 escaños). Estas características permiten evaluar el grado de competencia entre candidatos del mismo partido por las plazas, los niveles de penetración de los candidatos y el impacto de la organización o afiliación local en los resultados obtenidos por el partido en elecciones para cargos nacionales.

El primer indicador que se desea examinar aquí es la evolución del número de afiliados por mil electores entre 1994 y 2010. En particular, se desea saber si durante este período se observó algún cambio territorial claro en la densidad de afiliación de los principales partidos o si el patrón predominante ha sido homogéneo. 
El Mapa I presenta resultados bastante interesantes desde la perspectiva de la concentración territorial de los principales partidos. En el momento inicial del análisis (1994), la mayoría de ellos presentaba niveles relativamente bajos de afiliación, con números inferiores a 5 afiliados por 1000 electores. En los municipios pequeños esta fracción (de 5 afiliados) representaría un número absoluto ínfimo y puede considerarse bastante baja incluso para las medianas y grandes ciudades.

Tales niveles bajos de afiliación sólo son superados en algunos casos como el del PMDB, que desde la transición a la democracia se ha configurado como el principal partido local en el sistema partidario brasileño. Aun así se averigua que este último partido ha tenido sus bases de militancia concentradas en el Centro-Sur del país y en algunos puntos específicos de la región Noreste, con escasa penetración en el Norte y en algunos estados del Centro-Oeste del país.

El DEM, antiguo PFL, principal partido de la derecha, era el segundo con mayor densidad de afiliados, aunque con penetración variada en los estados y regiones. En particular, se destacan los estados de Santa Catarina, Mato Grosso y el Sur de Minas Gerais al mismo tiempo que sorprenden los bajos niveles de afiliación en Bahía y en el Noreste en general, enclave electoral histórico del partido.

El PDT revela una concentración de afiliados en los dos estados que condicionaron fuertemente sus primeros años: Río de Janeiro y Río Grande do Sur. La figura de Leonel Brizola (que ha sido gobernador en ambos estados por el mismo partido), constituye un elemento representativo de esa mayor incidencia de afiliados en los dos estados. El mismo patrón se observa para los demás partidos, que en este primer momento todavía se encuentran condicionados a sus orígenes y limitaciones organizativas inaugurales.

El cuadro observado en 2010, no obstante, revela un cambio bastante significativo en la distribución territorial de tales partidos. El hecho más evidente es que aumenta la densidad de afiliados en todos ellos. De una inmensa mayoría de municipios con menos de 5 afiliados por mil electores en 1994 (con la excepción del PMDB), expanden significativamente los niveles de afiliación en 2010.

Además, este fenómeno se observa en todo el territorio nacional, lo que confirma las evidencias anteriores de una mayor cobertura territorial de los partidos asociada al aumento de la densidad de la afiliación. Aunque en algunos casos exista cierta concentración regional (en especial en el Centro-Sur) como es el caso del PDT, la expansión territorial de la afiliación resulta evidente.

La combinación de estos dos elementos: aumento de la densidad de afiliación entre 1994 y 2010 y el hecho de que esto sucediera en todo el territorio nacional para la mayor parte de los grandes partidos constituye más una evidencia de la asociación entre esos dos indicadores como elementos centrales para explicar el comportamiento sistemático de los partidos brasileños en cuanto a su organización.

Otro elemento fundamental que se extrae de tales informaciones es el hecho de que los partidos se encuentran más cerca del electorado y han expandido su capacidad de movilización social. Quizás los niveles no sean lo suficientemente altos para que se celebre un cambio radical en el poco arraigo social que la mayor parte de los 
partidos brasileños han presentado históricamente, pero constituye una evidencia de un mayor acercamiento y penetración social.

\section{MAPA I}

AFILIADOS POR MIL ELECTORES DE LOS PRINCIPALES PARTIDOS

$$
\text { a) } 1994
$$
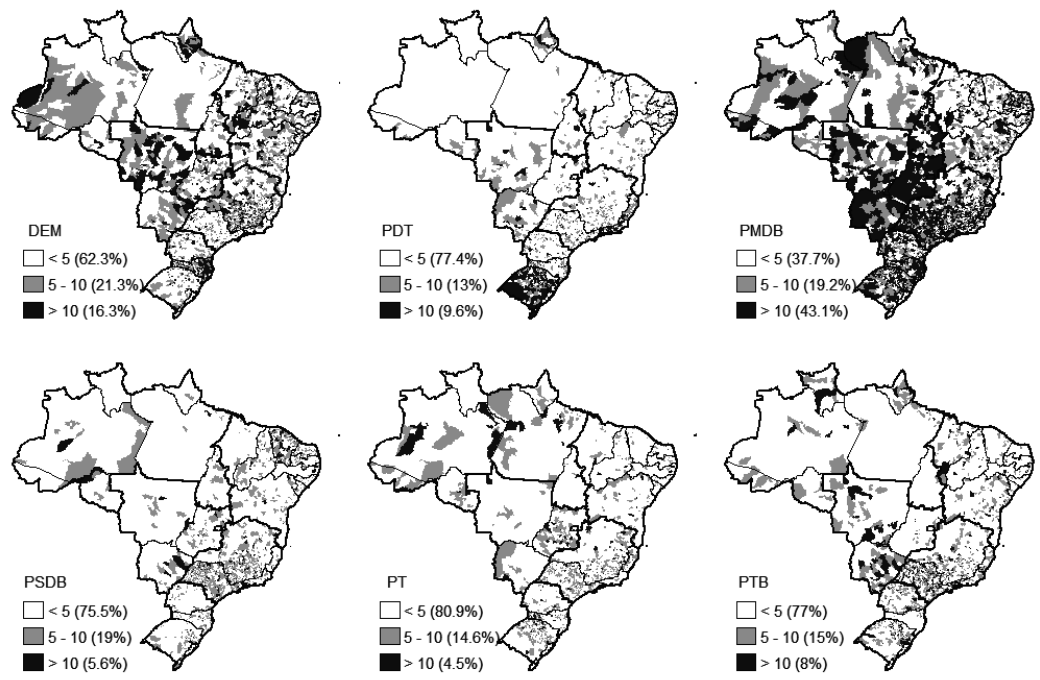

b) 2010
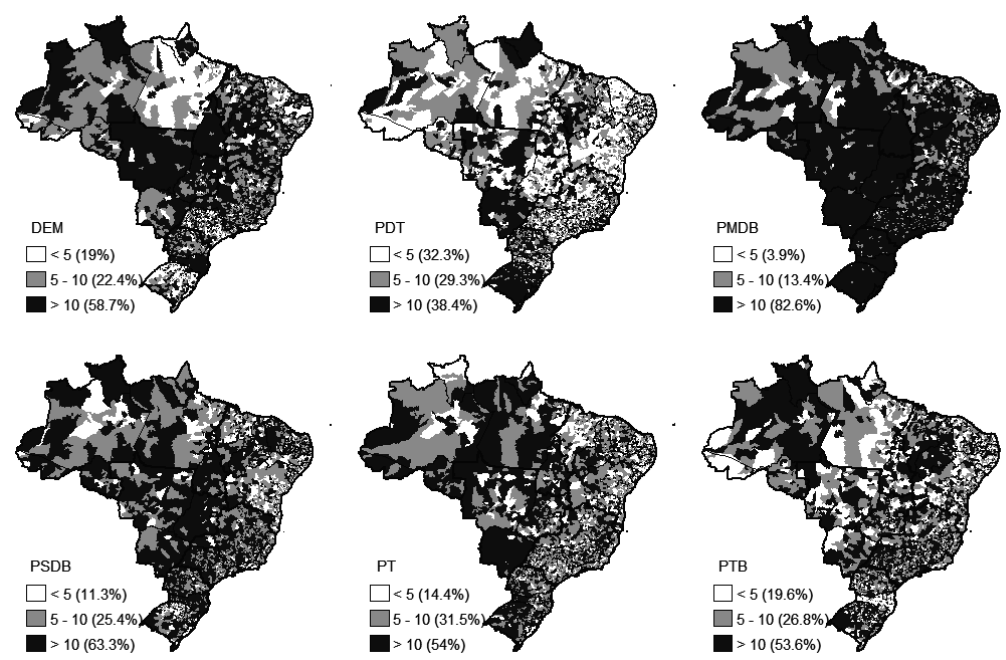

Fuente: Elaboración propia a partir de datos del TSE (1994-2010). 
MARIA DO SOCORRO SOUSA BRAGA, RODRIGO RODRIGUES-SILVEIRA Y TIAGO BORGES ORGANIZACIÓN, TERRITORIO Y SISTEMA PARTIDARIO: DIFUSIÓN TERRITORIAL

DE LA ORGANIZACIÓN DE LOS PARTIDOS Y SUS POTENCIALES IMPACTOS SOBRE...

Un estudio más abarcador de la relación de los partidos con los movimientos sociales (más allá del РT) en especial en las localidades podría revelar algunas tendencias de cambio o procesos de mayor «inclusividad» social que difícilmente podrán ser explicados desde una perspectiva cuantitativa como la adoptada en este trabajo.

Cuando se pasa al examen del porcentaje que cada partido posee del total de afiliados en cada municipio, el cuadro resulta bastante distinto del anterior (Mapa II). Aunque los grandes partidos hayan aumentado la densidad de afiliación en todo el país, el PMDB se revela como el partido con la mayor proporción de municipios en que posee más de $20 \%$ del total de afiliados.

En ese sentido, el PMDB representa sólidas bases locales de afiliación que le hacen capaz de mantener una cobertura territorial predominante en la mayor parte del país. Quizás esta sea una de las principales razones del sólido y constante desempeño del partido en las elecciones para diputado federal (y en los comicios locales), incluso con la existencia de profundas divergencias entre diferentes corrientes al interior del partido.

\section{MAPA II}

PORCENTAJE DE AFILIADOS EN LOS PRINCIPALES PARTIDOS CON RELACIÓN AL TOTAL DE AFILIADOS EN CADA MUNICIPIO (2010)
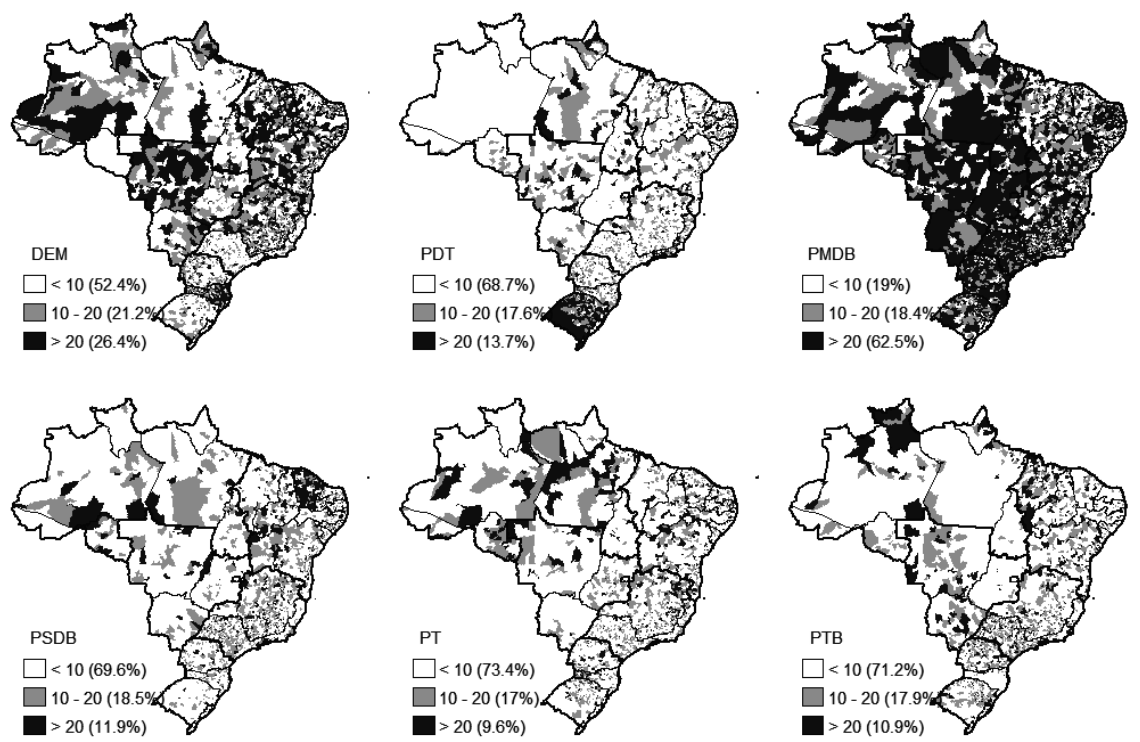

Fuente: Elaboración propia a partir de datos del TSE (2010).

Aunque el PMDB haya sido hasta 2010 el mayor partido parlamentario en la Cámara de diputados y lo siga siendo en el Senado, resulta sorprendente el hecho de que el partido no haya podido convertir dicha ventaja en votos presidenciales. Sólo el PSDB y el 
PT han sido capaces de liderar coaliciones partidarias lo suficientemente fuertes para ganar elecciones a presidente. Una explicación posible sería que, aunque el PMDB posea la organización local más sólida, esta última no resulta ser una condición suficiente para ganar la presidencia.

El segundo partido en términos de dominancia de la afiliación es el DEM que -a pesar de su reciente declive político en las últimas elecciones y la pérdida de muchos escaños en el Legislativo federal- se revela con una proporción relativamente importante de afiliados en muchos municipios del Noreste y parte de las regiones Norte, Centro-Oeste, Sureste (Minas Gerais) y Sur (en particular Santa Catarina).

Como en el Mapa I, los demás partidos presentan una concentración territorial del porcentaje de afiliados en algunos estados específicos. El PDT en sus partidos de origen y base histórica: Río Grande do Sul y Río de Janeiro. El PSDB en Ceará, mientras que el PTB en Roraima y el PT sin un patrón claro de concentración espacial.

Como se puede observar en la Tabla IV, 14 de los 28 partidos estudiados poseen algún tipo de organización partidaria en más de la mitad de los municipios brasileños. Sin embargo, la mayor parte está conformada por comisiones provisorias, algo que por su propio nombre revela el carácter temporal y poco institucionalizado de tales organismos.

Un esfuerzo que quizás sea más revelador consiste en intentar conocer aquellos municipios en que se observa el mayor número de directorios partidarios. El hecho de que varios partidos se esfuercen para construir una base organizacional más solida en un mismo municipio constituye una señal de que este municipio puede representar alguna ventaja electoral o política importante y que, por tanto, resulta razonable que los partidos inviertan recursos para crear una base más institucionalizada en estos lugares.

El Mapa III representa aquellos municipios que poseen cuatro o más directorios locales de los seis principales partidos representados en los mapas anteriores. Se utilizan dos métodos para representar los focos de concentración organizativa de los partidos. El primero consiste en generar un mapa de densidad de puntos: aquellos municipios que poseen directorios de cuatro partidos están representados por un cuadrado, los con cinco por un triángulo y los con seis por un círculo. El segundo trata de establecer zonas centrales o núcleos (kernel, en inglés) en que se concentran particularmente tales municipios ${ }^{7}$.

El análisis conjunto de los dos mapas revela que, en la medida que aumenta el número de directorios, se reduce significativamente el número de municipios y se queda clara una concentración territorial en tres focos regionales. Los cuadrados se encuentran mucho más dispersos y en mayor número que los demás. Los triángulos resultan más concentrados, aunque con una distribución similar a la del grupo anterior y los círculos se concentran en puntos específicos, pero con un enfoque territorial marcado en el Río Grande do Sul.

7. Más información sobre los mapas de densidad de puntos y la metodología de análisis de kernel puede encontrarse en T. Slocum (1999), B. Dent (1999) e Y. Lu (2000). La distancia (bandwidth) utilizada para el cálculo de la densidad de kernel ha sido de $100 \mathrm{~km}$. 
MARIA DO SOCORRO SOUSA BRAGA, RODRIGO RODRIGUES-SILVEIRA Y TIAGO BORGES ORGANIZACIÓN, TERRITORIO Y SISTEMA PARTIDARIO: DIFUSIÓN TERRITORIAL

DE LA ORGANIZACIÓN DE LOS PARTIDOS Y SUS POTENCIALES IMPACTOS SOBRE..

Esto lleva al segundo aspecto de interés que consiste en la concentración de los puntos en algunas regiones particulares del territorio Brasileño. Se destacan tres clusters territoriales de los municipios en que se observa la coincidencia de directorios de los seis principales partidos. El más importante de ellos se encuentra en el estado de Río Grande do Sul donde existe una acentuada concentración de los tres grupos. El segundo cluster se encuentra localizado en la región que comprende el estado de São Paulo, el Sur y parte del Este de Minas Gerais y Espirito Santo. Finalmente, se averigua un cluster nordestino, especialmente importante en los estados de Río Grande do Norte, Paraíba y Alagoas.

Las zonas más oscuras o de intensidad más acentuada en el Mapa IIIb reflejan, por tanto, una mayor concentración de municipios con al menos cuatro directorios partidarios municipales. En la medida que la distancia a estos tres focos de concentración aumenta, la intensidad del color disminuye hasta perder total significado.

MAPA III

MUNICIPIOS CON CUATRO O MÁS PARTIDOS CON DIRECTORIOS LOCALES (2011)

(a) Densidad de puntos

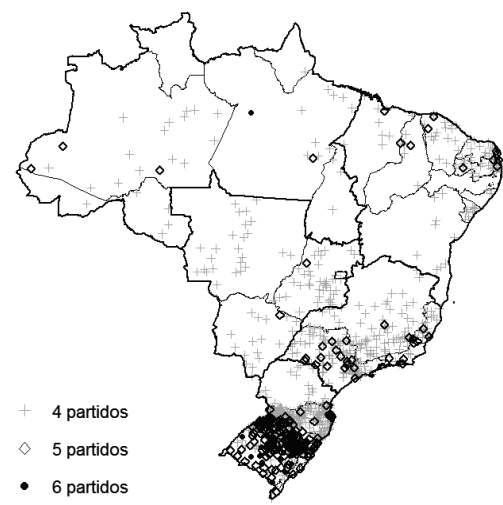

(b) Densidad de Kermel

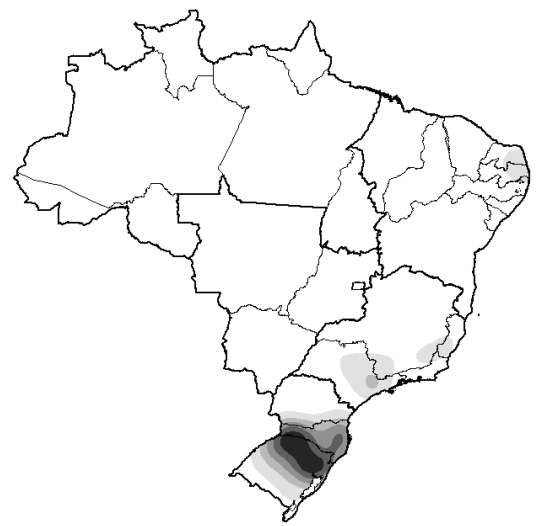

Fuente: Elaboración propia a partir de datos del TSE (2011).

Por otra parte, estos patrones de puntos en forma de clusters revelan las localidades en las que existe una mayor disputa electoral entre diversos partidos. En el Noreste, algunas fuerzas regionales como el PSB o el PPS poseen fuerte penetración, lo que dificulta un mayor éxito electoral de los grandes partidos. En Río Grande do Sul, se observa el reducto de varios partidos como el PDT el PP y el PT, aunque también formen parte de las disputas el PMDB y el PSDB que han sido capaces de obtener el gobierno del estado en algunas ocasiones.

Eso se refleja en parte en el número de candidatos que obtiene voto en cada municipio. El Mapa III se vincula de forma muy cercana al Mapa IV, pues se puede ver que 
la nube de puntos se acerca a la distribución de candidatos de la mayoría de los partidos. Se percibe la concentración de un mayor número de candidatos en la franja este que va desde el Sur hasta el Noreste del país.

En gran medida dicha concentración se explica por la densidad demográfica más acentuada en esta región. Sin embargo, esta variable por sí misma actúa sólo indirectamente sobre tales resultados. La representación legislativa a nivel federal depende directamente de la proporción de la población total que cada estado posee. Así que estados con un mayor número de escaños tenderán a poseer una mayor concentración de candidatos y la competencia entre candidatos de un mismo partido.

Además, se debe señalar un factor adicional: el número de municipios de cada estado y el grado de concentración de la población en algunos municipios en ciertos estados. Estados con pocos municipios y con un número reducido de población tienden a presentar menor nivel de competitividad entre candidatos de un mismo partido. Esto sugiere una estrategia territorial racional de los partidos que evitan lanzar un número elevado de candidatos que pudiese perjudicar las oportunidades del partido de obtener los escaños en disputa.

MAPA IV

NúMERO DE CANDIDATOS A DIPUTADO FEDERAL DE CADA PARTIDO QUE HAN OBTENIDO VOTOS EN EL MUNICIPIO (2010)
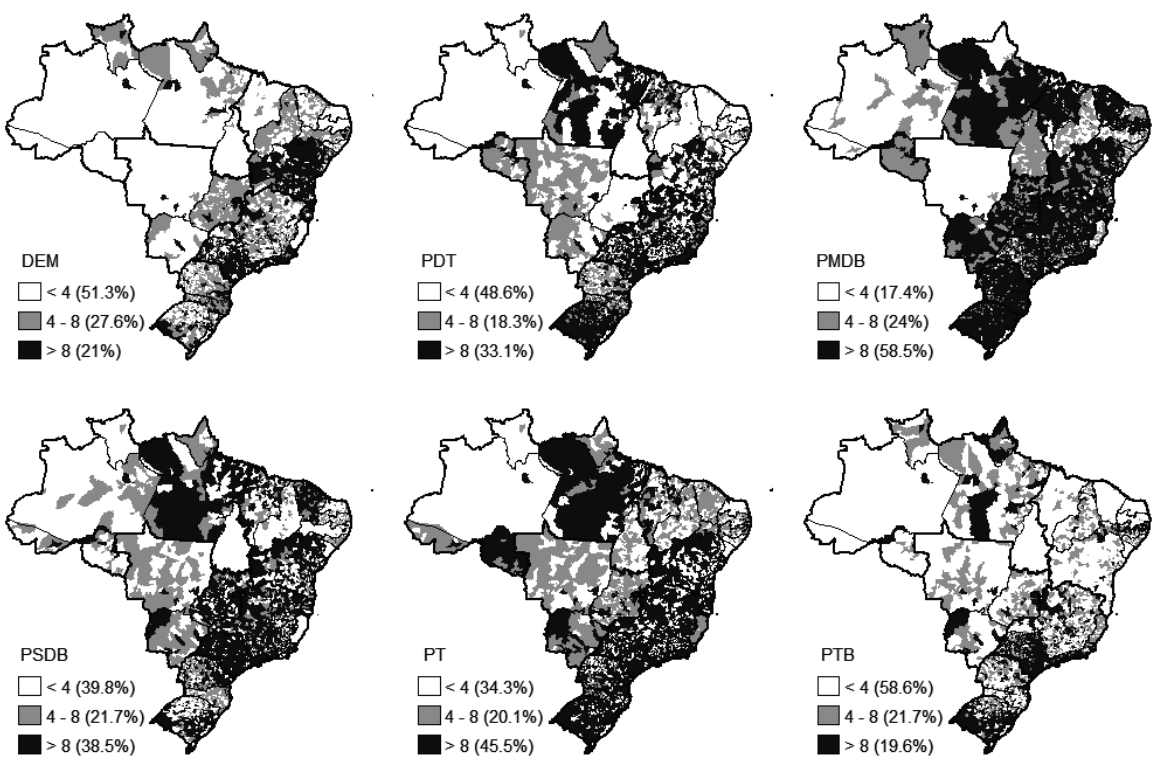

Fuente: Elaboración propia a partir de datos del TSE (2010).

Por otro lado, el mayor número de candidatos en estados con alta población y con muchos municipios ayudaría al partido a obtener un cociente electoral más elevado y, 
por consiguiente, compensar en parte el personalismo del sistema de lista abierta. La lógica para este grupo de localidades sería: cuantos más candidatos mayor el total de votos en el partido y mayor el cupo de escaños a ser obtenido por el partido. La cobertura del mayor número posible de ciudades, en ese sentido, actuaría como un dispositivo partidario y se configuraría como una estrategia territorial de maximización de los votos en términos agregados.

En su conjunto estos resultados sugieren una sistematicidad en la evolución reciente de los partidos políticos brasileños y el hecho de que su perfil organizativo puede tener consecuencias importantes sobre los resultados electorales obtenidos. Sin embargo, tal relación consiste en solamente un indicativo y una hipótesis de trabajo que requiere una investigación más detallada en el futuro para determinar si se confirma o no. El estudio de Mainwaring (1991) parece haber captado un momento muy inicial en la evolución organizativa de los partidos brasileños, que recién habían dejado 21 años de dictadura militar y empezaban a estructurarse. Once años después de ese estudio, los datos sobre afiliación y organización sugieren la necesidad de revisión de este argumento y una mirada más atenta a las condiciones institucionales que garantizan la estabilidad del sistema partidario brasileño en la actualidad.

\section{CONSIDERACIONES Finales}

A pesar de ser centrales en las explicaciones sobre el surgimiento, desarrollo y crisis de las organizaciones partidarias, la cantidad y la dispersión de afiliados y directorios partidarios han recibido escasa atención empírica. El presente artículo tuvo como principal objetivo investigar el desarrollo organizacional de los partidos brasileños a partir de tales elementos, buscando identificar patrones de distribución espacial que ayudaran en la mejor comprensión de las organizaciones que vienen demostrando su consolidación en la actual experiencia democrática brasileña.

Luego de una revisión bibliográficas que ha destacado la afiliación clásica de los propósitos adoptados en este trabajo, el análisis empírico ha representado la identificación de elementos importantes de los partidos brasileños en relación a la estructura organizacional y la evolución de la cantidad de afiliados, en un examen que ha incorporado también medidas de densidad y expansión o cobertura territorial.

El primer aspecto de relieve encontrado corresponde a una identificación entre dos perfiles de afiliación entre partidos grandes o medianos y pequeños: mientras que en los primeros se ha constatado un patrón de altos niveles de cobertura iniciales con una rápida expansión en la densidad de los afiliados, en los últimos se ha observado una relación casi lineal entre cobertura territorial y expansión de los afiliados, además de posiciones iniciales bastante reducidas.

Sin embargo, a pesar de diferencias importantes entre partidos grandes y pequeños, el principal aporte de este trabajo resulta de señalar la centralidad de la expansión territorial y de la densidad de afiliación en las estrategias territoriales de los partidos brasileños como un todo. Comúnmente tratados como frágiles y con pretensiones exclusivamente 
electorales, los partidos han sido estudiados desde la perspectiva que considera la inversión en la estructura organizacional como un recurso utilizado por los liderazgos partidarios para controlar el partido y ganar elecciones.

Los resultados obtenidos aquí demuestran que las organizaciones y el nivel de afiliación pueden servir también para otros propósitos. En primer lugar, los tres principales partidos a nivel nacional son también aquellos que poseen los niveles más altos de institucionalización organizacional. Además, las bases territoriales locales pueden servir no sólo para resolver disputas internas como fundamento para la construcción de alianzas o coaliciones políticas a nivel subnacional que ayuden a lograr objetivos nacionales. En ese sentido, las estructuras partidarias en Brasil sí importan en la medida que al mismo tiempo permiten la consolidación de un partido a nivel local, pero también ayudarían a establecer límites para el desarrollo territorial de otros partidos.

Sin embargo, la influencia directa en los resultados electorales tanto de la organización como de los niveles de afiliación debe ser investigada de modo más minucioso en el futuro. Lo que se ha observado es una coincidencia entre aquellos partidos de mayor expresión nacional (en particular en el Legislativo) y mayores niveles de afiliación y mayor formalidad organizativa. Cabe investigar si tal relación realmente es significativa o si su éxito electoral se debe a otros factores más allá de los aspectos organizativos.

Existen diversas lagunas a que los estudiosos deben atenerse. La primera de ellas consiste en averiguar el formato de la relación entre organización y voto. Como se ha podido ver en el desarrollo del trabajo para el caso de la cobertura territorial y el nivel de afiliación, la asociación entre las diferentes dimensiones de la política puede asumir comportamientos que no siempre son lineales. En ese sentido, se deben revisar críticamente los modelos utilizados (en general lineales) para analizar las relaciones políticas.

Otro elemento de carácter metodológico que llamó la atención durante la realización del presente trabajo ha sido la necesidad de mirar el sistema político desde diferentes escalas. En muchos casos, la comprensión de los datos nacionales sólo se hizo posible por un examen más detenido de las realidades subnacionales de los partidos. Por otro lado, hacer el zoom hacia algunas regiones o estados ha permitido desvelar dinámicas de competencia nacionales que convergen en un punto del territorio, como es la concentración particularmente significativa de los directorios de los principales partidos en el Rio Grande do Sul, parte del Sureste y del Noreste.

Luego de aproximadamente 30 años desde la inauguración del sistema de partidos actual, la desconfianza con relación a los partidos brasileños parece disminuir progresivamente. La mayor parte de la evidencia presentada en este trabajo refuerza la conclusión de que realmente existe una mayor consolidación de los partidos en todos sus niveles, aunque preocupa la alta informalidad organizacional de muchos de ellos, en particular los de la derecha.

Los próximos pasos consistirían en desarrollar el entendimiento de los engranajes de los partidos, enfatizando particularmente cómo éstos se vinculan a los resultados electorales. Se trata de un paso fundamental para conocer el impacto real de los cambios organizacionales y el avance en la penetración social de los partidos apuntados en el 
MARIA DO SOCORRO SOUSA BRAGA, RODRIGO RODRIGUES-SILVEIRA Y TIAGO BORGES ORGANIZACIÓN, TERRITORIO Y SISTEMA PARTIDARIO: DIFUSIÓN TERRITORIAL

DE LA ORGANIZACIÓN DE LOS PARTIDOS Y SUS POTENCIALES IMPACTOS SOBRE...

presente trabajo sobre el comportamiento y la relación de los ciudadanos con la política y las instituciones democráticas en Brasil.

\section{BiBLIOGRAFÍA}

AgNew, John. Mapping Politics: How Context Counts in Electoral Geography. Political Geography, 1996, vol. 15: 129-146.

AGNEW, John. The Dramaturgy of Horizons: Geographical Scale in the 'Reconstruction of Italy' by the New Italian Political Parties, 1992-95. Political Geography, 1997, vol. 16: 99-121.

AldrICH, John. Why Parties?: The Origin and Transformation of Political Parties in America. 1. ${ }^{\text {a }}$ edición. Chicago/London: The Chicago University Press, 1995.

Aldrich, John. Political Parties In and Out of Legislatures. En RodHES, R. A. W.; Binder, S. A. y Rockman, B. A. The Oxford Handbook of Political Institutions. Oxford: Oxford University Press, 2006: 555- 576.

Amaral, Oswaldo. Ainda conectado: o PT e seus vínculos com a sociedade. Opinião Pública, 2011, vol. 17 (1): 01-44.

Braga, Maria do Socorro S. O Processo Partidário-Eleitoral Brasileiro: Padrões de Competição Política 1982-2002. 1. ${ }^{a}$ edición. São Paulo: Humanistas/Fapesp, 2006.

Braga, Maria do Socorro S. y Borges, Tiago. Organização e Poder nos Partidos Políticos Brasileiros. VI Encontro da Associação Brasileira de Ciência Política, Campinas, 2008.

Calvo, Ernesto y Escolar, Marcelo. The Local Voter: A Geographically Weighted Approach to Ecological Inference. American Journal of Political Science, 2003, vol. 47 (1): 189-204.

Carneiro, Leandro Piquet y Almedia, Maria Hermínia Tavares de. Definindo a Arena Política Local: Sistemas Partidários Municipais Na Federação Brasileira. Dados - Revista De Ciências Sociais, 2008, vol. 51 (2): 403-432.

CARTY, Roland Kenneth y EAgLES, Munroe. The Political Ecology of Local Party Organization: The Case of Canada. Political Geography, 1998, vol. 17 (5): 589-609.

Cox, Gary W. The Efficient Secret: The Cabinet and the Development of Political Parties in

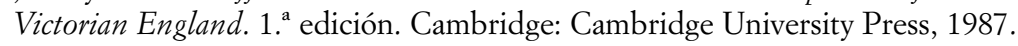

DAHL, Robert. Polyarchy: participation and opposition. 1. ${ }^{a}$ edición. New Haven: Yale University Press, 1971.

Dent, Borden D. Cartography: Thematic Map Design. Boston: WCB/McGraw-Hill, 1999.

Duverger, Maurice. Os Partidos Políticos. 1. a edición. Rio de Janeiro: Martins Fontes, 1954.

Duverger, Maurice. Los Partidos Políticos. 19. ${ }^{a}$ edición. Ciudad de México: Fondo de Cultura Económica, 2004.

ERLINGsson, Gissur Ó. The Spatial Diffusion of Party Entrepreneurs in Swedish Local Politics. Political Geography, 2008, vol. 27 (8): 857-874.

GoodCHILD, Michael F. y JANELle, Donald. Spatially Integrated Social Sience. 1. a edición. Oxford: Oxford University Press, 2004.

Gunther, Richard y Diamond, L. Species of political parties: a New Typology. Party Politics, 2003, vol. 9 (2): 167-199.

Johnston, Ron y PATTIE, Charles. Putting Voters in Their Places: Geography and Elections in Great Britain. Oxford: Oxford University Press, 2004.

Katz, Richard y MAIR, Peter. Party Organizations. 1. a edición. London: Sage Publications, 1992.

Katz, Richard y MaIR, Peter. How Parties Organize. Change and Adaptation in Party Organiza-

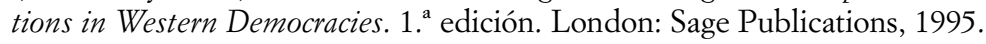


MARIA DO SOCORRO SOUSA BRAGA, RODRIGO RODRIGUES-SILVEIRA Y TIAGO BORGES ORGANIZACIÓN, TERRITORIO Y SISTEMA PARTIDARIO: DIFUSIÓN TERRITORIAL DE LA ORGANIZACIÓN DE LOS PARTIDOS Y SUS POTENCIALES IMPACTOS SOBRE..

Kirchimer, Otto. The Catch-All Party. En MaIr, P. The West European Party System. 1. a edición. Oxford: Oxford University Press, 1990: 50-60.

KINZO, Maria Dalva Gil. Oposição e Autoritarismo: Gênese e trajetória do PMDB (1966-1979). 1. ${ }^{a}$ edición. São Paulo: IDESP/Vértice, 1988.

KINZO, Maria Dalva Gil. Partidos, eleições e democracia no Brasil pós-1985. Revista Brasileira de Ciências Sociais, 2004, vol. 19 (54): 23-40.

KINZO, Maria Dalva Gil. Os Partidos no Eleitorado: percepções públicas e laços partidários no Brasil. Revista Brasileira de Ciências Sociais, 2005, vol. 20 (57): 65-81.

LAMOUNIER, Bolívar. Estrutura Institucional e Governabilidade na década de 90. En REIS VELLOSO, João Paulo dos (ed.). O Brasil e as Reformas Políticas. Rio de Janeiro: José Olympio, 1992: $23-48$.

LAmounier, Bolívar y Meneguello, Rachel. Partidos políticos e consolidação democrática: o caso brasileiro. 1. a edición. São Paulo: Brasiliense, 1986.

La Palombara, Joseph y Weiner, M. Political Parties and Political Development. 1. a edición. Princeton, NJ: Princeton University, 1966.

LaWSON, Kay (org.). How Political Parties Work. Perspectives from within. 1. a edición. London: Westport Connecticut, 1994.

LimONGI, Fernando y CORTEZ, Rafael. As eleições de 2010 e o quadro partidário. Novos Estudos, 2010, vol. 88: 21-37.

Lu, Yongmei. Spatial Cluser Analysis for Point Data: Location Quotients Verses Kernel Density. University Consortium of Geographic Information Science (UCGIS), 2000.

MaInWaring, Scott. Políticos, partidos e sistemas eleitorais. Novos Estudos, 1991, vol. 29: 34 58.

MAINWARING, Scott. Sistemas partidários em novas democracias: o caso do Brasil. Rio de Janeiro/ Porto Alegre: Editora da FGV/Mercado Aberto, 2001.

MaYHEW, David. Congress: The Electoral Connection. 1. ${ }^{a}$ edición. New Haven: Yale University Press, 1974.

Melo, Carlos Ranulfo. Nem tanto ao Mar nem tanto a Terra: elementos para uma análise do sistema partidário brasileiro. En MELO, C. R. y SAEZ, M. A. A Democracia Brasileira: balanço e perspectivas para o século XXI. 1. ${ }^{\text {a }}$ edición. Belo Horizonte: Editora UFMG, 2011: 267-302.

MenEGUELO, Rachel. PT: a formação de um partido (1979-1982). 1. ${ }^{a}$ edición. Rio de Janeiro: Paz e Terra, 1989.

Michels, Robert. Os Partidos Políticos. 3. . edición. Brasília: UNB, 1971.

Ostrogorski, Mosei. A Democracia e os Partidos Políticos. 3. a edición. Paris: Seuil, 1979.

Panebianco, Angelo. Modelos de Partido. Organização e Poder nos partidos políticos. 2. edición. São Paulo: Martins Fontes, 2005.

PORTER, Jeremy R. y Howell, Frank M. Theoretical Foundations and Methodological Applications in the Sociology of Location. En Geographical Sociology. New York: Springer, 2012, vol. 105.

SAmuels, David. Determinantes do Voto Partidário em Sistemas Eleitorais Centrados no Candidato: Evidências sobre o Brasil. Dados, 1997, 40: em línea: http: //www.scielo.br/scielo. php?pid= S0011-52581997000300008\&script=sci_arttext.

SCHELESINGER, Joseph. On The theory of Party Organizations. Journal of Politics, 1984, vol. 46 (2): 369-400.

SHIN, Michael. The Politicization of Place in Italy. Political Geography, 2001, vol. 20 (3): 331 352. 
MARIA DO SOCORRO SOUSA BRAGA, RODRIGO RODRIGUES-SILVEIRA Y TIAGO BORGES ORGANIZACIÓN, TERRITORIO Y SISTEMA PARTIDARIO: DIFUSIÓN TERRITORIAL

DE LA ORGANIZACIÓN DE LOS PARTIDOS Y SUS POTENCIALES IMPACTOS SOBRE..

Shugart, Matthew S. y Carey, John. Presidents and Assemblies. Cambridge: Cambridge University Press, 1992.

Slocum, Terry A. Thematic Cartography and Visualization. Upper Saddle River, NJ: Prentice Hall, 1999.

TERRON, Sonia Luiza. A Composição De Territórios Eleitorais No Brasil: Uma Análise Das Votações De Lula (1989-2006). Tesis Doctoral. Rio de Janeiro: IUPERJ, 2009.

Tiemann, Guido. The Nationalization of Political Parties and Party Systems in Post-communist Eastern Europe. Communist and Post-Communist Studies, 2012, vol. 1-2: 77-89.

Weber, Max. Ciência e política: duas vocações. 3. ${ }^{2}$ edición. São Paulo: Cultrix, 1993.

Weber, Max. Partidos e Organização Partidária. En Economia e Sociedade. 5. a edición. Brasília: UNB, 1999.

Obras y sitios oficiales:

Estatuto del PMDB, PSDB, PT, PFL e PP.

Instituto Brasileiro de Geografia e Estatística.

Tribunal Superior Electoral. 